\title{
Comparison of Strength and OSTI Load-Based Methods for Testing Wind Turbine Blades
}

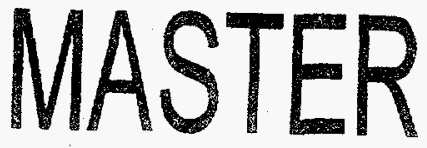

Walter D. Musial, Mèlissa E. Clark,

Nathaniel Egging

National Renewable Energy Laboratory

Golden, Colorado

Michael D. Zuteck

MDZ Consulting

Kemah, Texas

Prepared for

1997 ASME Wind Energy Symposium

Reno, Nevada

January 6-9, 1997

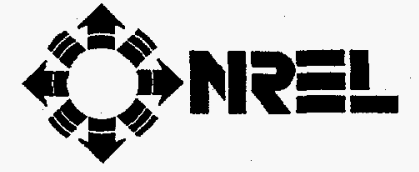

National Renewable Energy Laboratory

1617 Cole Boulevard

Golden, Colorado 80401-3393

A national laboratory of the U.S. Department of Energy

Managed by Midwest Research Institute

for the U.S. Department of Energy

under contract No. DE-AC36-83CH10093

Prepared under Task No. WE713040

November 1996 


\section{NOTICE}

This report was prepared as an account of work sponsored by an agency of the United States government. Neither the United States government nor any agency thereof, nor any of their employees, makes any warranty, express or implied, or assumes any legal liability or responsibility for the accuracy, completeness, or usefulness of any information, apparatus, product, or process disclosed, or represents that its use would not infringe privately owned rights. Reference herein to any specific commercial product, process, or service by trade name, trademark, manufacturer, or otherwise does not necessarily constitute or imply its endorsement, recommendation, or favoring by the United States govemment or any agency thereof. The views and opinions of authors expressed herein do not necessarily state or reflect those of the United States government or any agency thereof.

Available to DOE and DOE contractors from:

Office of Scientific and Technical Information (OSTI)

P.O. Box 62

Oak Ridge, TN 37831

Prices available by calling (423) $576-8401$

Available to the public from:

National Technical Information Service (NTIS)

U.S. Department of Commerce

5285 Port Royal Road

Springfield, VA 22161

(703) $487-4650$ 


\section{DISCLAIMER}

Portions of this document may be illegible in electronic image products. Images are produced from the best available original document. 


\section{DISCLAIMER}

This report was prepared as an account of work sponsored by an agency of the United States Government. Neither the United States Government nor any agency thereof, nor any of their employees, makes any warranty, express or implied, or assumes any legal liability or responsibility for the accuracy, completeness, or usefulness of any information, apparatus, product, or process disclosed, or represents that its use would not infringe privately owned rights. Reference herein to any specific commercial product, process, or service by trade name, trademark, manufacturer, or otherwise does not necessarily constitute or imply its endorsement, recommendation, or favoring by the United States Government or any agency thereof. The views and opinions of authors expressed herein do not necessarily state or reflect those of the United States Government or any agency thereof. 


\title{
COMPARISON OF STRENGTH AND LOAD-BASED METHODS FOR TESTING WIND TURBINE BLADES
}

\author{
Walter D. Musial \\ Melissa E. Clark \\ Nathaniel Egging \\ National Renewable Energy Laboratory \\ Golden, $\mathrm{CO}$ \\ Michael D. Zuteck \\ $\mathrm{MDZ}$ Consulting \\ Kemah, TX
}

\begin{abstract}
$\underline{\text { Abstract }}$
The purpose of this paper is to compare two methods of blade test loading and show how they are applied in an actual blade test. Strength and load-based methods were examined to determine the test load for an Atlantic Orient Corporation (AOC)15/50 wind turbine blade for fatigue and static testing. Fatigue load-based analysis was performed using measured field test loads extrapolated for extreme rare events and scaled to thirty-year spectra. An accelerated constant amplitude fatigue test that gives equivalent damage at critical locations was developed using Miner's Rule and the material S-N curves. Test load factors were applied to adjust the test loads for uncertainties, and differences between the test and operating environment. Similar analyses were carried out for the strength-based fatigue test using the strength of the blade and the material properties to determine the load level and number of constant amplitude cycles to failure. Static tests were also developed using load and strength criteria. The resulting test loads were compared and contrasted. The analysis shows that, for the AOC $15 / 50$ blade, the strength-based test loads are higher than any of the static load-based cases considered but were exceeded in the fatigue analysis for a severe hot/wet environment.
\end{abstract}

\section{Introduction}

The methodology for testing full scale wind turbine blades differs widely among laboratories around the world. Test laboratories are constrained by the available test equipment which limits the type of test loading. Beyond the fixed hardware constraints there is no universal agreement among test labs or certification agencies about what tests should be conducted and how severe a test should be. National design standards differ in approach, making the transfer of some test results difficult. A detailed comparison is given by van Grol et al. ${ }^{\text {I }}$ Steps toward better agreement are underway through an International Electro-technical Commission (IEC) TC88 initiative and other European harmonization programs. $^{2}$

Most agree that the test loading applied during a full scale blade test must be modified from the original design operating loads for practical reasons imposed by the test hardware and schedule. Also, most agree that at least one test objective should be to validate the blade design assumptions. To do so, the test load must be evaluated against the design loads. ${ }^{3}$ This paper describes two approaches used to determine the test loads for a blade test from which such an evaluation may be done: test loads based on calculated strength and a test loads based on the design loads.

For the load-based case, the test load is derived from a combination of design loads representing a condition or concurrent conditions the wind turbine must be able to survive without damage. These design loads are determined by scaling the characteristic loads by partial safety factors (PSF) specified by the design standard used in the design. Further adjustments are made to the design loads to arrive at the target test load. These adjustments, or test load factors (TLF), account for uncertainties introduced by the test equipment and methodology, and for differences between operating and test environments.

A load-based test verifies the blade's ability to withstand a particular load combination, but even after a successful test many areas of the blade may still be under-loaded relative to the blade's ability to carry the load. This happens because the designer has to consider other influences not represented by the test load case. A good example is a fatigue-driven blade design that results in excessive reserve margins on ultimate strength at several spanwise locations when tested under extreme static loading. Conversely, compensating for buckling sensitivity in thin walled blade structures could produce unnecessarily high 
fatigue margins. This additional capacity has been described as a fatigue stress factor or reserve strength factor. ${ }^{4}$ For a fatigue test, this would be the difference between the loads representing the design life equivalent and the fatigue loads which would result in a damage equal to 1 , using a Palmgren-Miner analysis. For a static test, it is generally the difference between the ultimate failure strength and the test loads representing an extreme event.

For a strength-based test, the test load is derived from a spanwise distribution of the predicted design strength of the test blade. Since the strength of a blade is set by a variety of fatigue and extreme load conditions, that sometimes come from multiple directions, the shape of the spanwise design load distribution for a particular load condition is unlikely to correspond to the shape of the strength distribution. A strength-based test will, however, be crafted to match the spanwise blade strengths in a particular direction. In a strength-based test, the test load can include much of the reserve strength and usually yields a more severe test load. If the blade is tested to its design strength, the design methodology is verified for all of the load cases encornpassed by the strength-based loads, providing that the design strength calculations were correct. This would be convenient when a manufacturer is unsure on what standard the test loads should be based.

\section{General Methodology}

\section{General Load-Based Testing}

Load-based testing is used to determine if a blade is capable of carrying a particular load or load combination. The representative loads are determined through testing or analysis for the load combination of interest. The characteristic load is the representative load value which has an accepted probability of not being unfavorably exceeded during some established reference period. ${ }^{6}$ The PSFs used in the design are applied to scale the characteristic loads to the design loads. The value of these PSFs will vary depending on the design standard used. Fatigue tests will have different factors than static tests. Additional test load factors are applied to the design loads in order to account for uncertainties introduced by the test equipment and methodology, and differences between operating and test environments. Several influences must be considered for each. For example, higher temperatures and humidity in the actual operating environment are accounted for in an environmental effects factor. Another factor accounts for uncertainties in the fatigue formulation (e.g. for accelerated loading), and errors due to necessary simplifications associated with the test equipment (e.g. point loading). ${ }^{3}$ These additional test uncertainties usually make the test loads higher than design loads and they must be determined for each specific blade test. The target test loads are established by combining the TLFs with the PSFs used in the design. The target test loads are approximated by the test loading equipment, as perfect duplication of ideally distributed surface loading is nearly impossible using standard laboratory equipment. For a typical design verification test, the test is considered successful if the blade survives the prescribed test loading without a failure. Further information about failure modes, manufacturing quality, and reserve strength can be obtained if the testing is continued to blade failure.

\section{General Strength-Based Testing}

For strength-based testing the target test loads are derived directly from the computed blade strength. The blade strength must be adjusted to account for laboratory differences such as environmentally benign conditions. The test loads approximate the strength curve as closely as possible with the same test equipment limitations as the load-based test. The loading or number of cycles are increased until a failure occurs. The test loads at failure provide a reference for blade strength which is not dependent on TLFs or design load PSFs. For most points on the blade, this spanwise strength distribution will be greater than the load requirements for any particular load condition because the strength is developed for all load cases. Therefore, each point along the blade span is tested closer to its maximum capacity. Subsequent load evaluations can be performed for any load combination in the test load direction to verify a blade design for a particular standard.

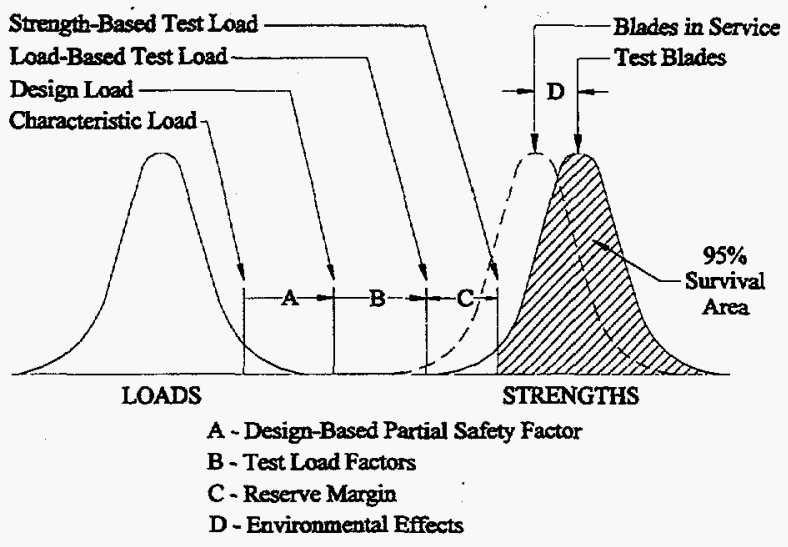

\section{Figure 1 - Generalized Application of Load Factors for Wind Turbine Blade Testing}

Figure 1 illustrates the relationship between generic loads and strengths and how the design PSFs and TLFs are applied to blade testing. Note that in a load-based 
test, the design load PSFs and TLFs (A and B) are ostensibly stacked on the characteristic load to arrive at the load-based test load.* The remainder, $(C)$, between the load-based test load and the strength-based test load is the reserve strength. Note that the reserve strength can be less than zero if a blade fails before the test load is reached.

A strength-based test is concerned only with the right side of Figure 1. It uses the $95 \%$ survival value on the "test blade" distribution to set a proof test load with a high probability of not failing the blade. This paper focuses on tests-to-failure where the mean blade strengths are used to set the strength-based loading and the actual strengths are determined by the load-at failure. Note that the test blade strengths are higher than the in-service blade strengths due mostly to environmental influences on the material properties mentioned earlier.

\section{Description of $\underline{A O C} \underline{15 / 50}$ Blade}

An Atlantic Orient Corporation (AOC) 15/50 wind turbine blade was used to demonstrate the two methods described above for both static and fatigue evaluations. At the time of this paper, tests of the blades were still underway and test results were not available, but the methods are of more central importance to this discussion.

The turbine manufacturer is Atlantic Orient Corporation of Norwich, VT. The original AOC $15 / 50$ blade design was manufactured by Gougeon Manufacturing Company (GMC) in Pinconning, MI and fatigue tested at the National Renewable Energy Laboratory (NREL). ${ }^{7}$ Recently, AOC has contracted Aerpac of the Netherlands to build their blades. A new series of blade tests have begun at NREL to validate this new blade source.

The blade uses the same wood/epoxy construction and the same external geometry as the original GMC blade. It is $7.2 \mathrm{~m} \mathrm{(284} \mathrm{in.)} \mathrm{long} \mathrm{and} \mathrm{attaches} \mathrm{to} \mathrm{the} \mathrm{turbine's}$ hub $0.28 \mathrm{~m}$ (11 in.) from the center of rotation. The veneer schedule is shown in Figure 2 for one side of the blade's skin. Note that the vertical scale is enlarged to show how the veneers are stacked, with all ply drops occurring on the interior surface. The root buildup on the left side is necessary to house the ten, $19.05-\mathrm{cm}$ $(7.5$-in.) long tapered steel studs with $15.9-\mathrm{mm}(5 / 8 \mathrm{in}$.)

\footnotetext{
* Under IEC 1400-1 design guidelines, the material partial safety factor is applied in the design as a reduction in strength from coupon test samples to the actual blade. For a blade test, the blade test specimen already embodies these design safety factors and they should not be applied again to the test load.
}

threaded holes. The studs are bonded into tapered holes, which are drilled axially into the root buildup at the root separation plane ( $3.73 \%$ span), using a thickened epoxy mixture. There are three primary locations along the blade span that limit the blade strength in fatigue and static loading: the root and two "wide" butt-joint regions at 30\%-36\%, and 64\% - 68\% of span. These were the critical test areas. The butt joints are termed wide because the veneers are spaced approximately $6 \mathrm{~mm}(0.25 \mathrm{in})$ apart at the joint to give better tensile fatigue properties.

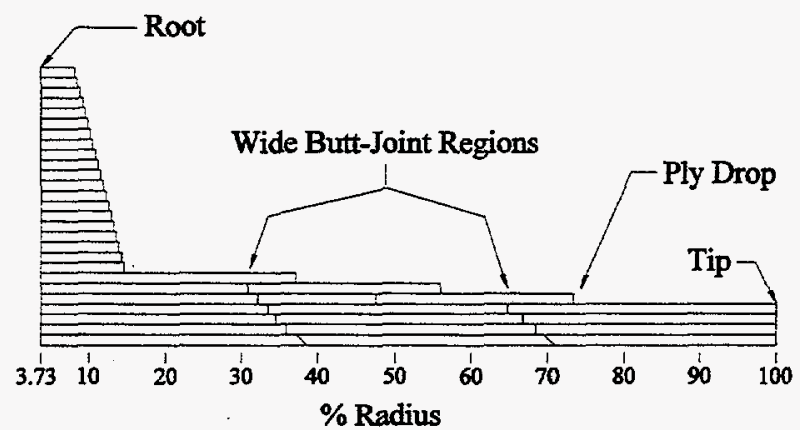

Figure 2 - Veneer Schedule for AOC 15/50 Blade

The AOC $15 / 50$ blade provides a good example of a blade with differing strength and load characteristics. The strength of the blade about various bending axes does not match any particular load distribution because the strength of the blade is a composite of several load cases and the construction is driven by many practical constraints that affect the strength. For instance, the veneer drop-off locations are chosen to make most efficient use of the parent veneè (for cost efficiency) while simultaneously assuring that ply drops occur beyond butt joint regions (for strength optimization).

\section{$\underline{\text { Static Testing }}$}

\section{Static Load-based Testing}

All of the design loads for the AOC 15/50 turbine follow the IEC Class II wind turbine standards ${ }^{8}$ which are based on the generally accepted ISO standard $2394 .{ }^{6}$ A load-based test load was developed using the characteristic loads for the extreme 50-year wind gust conditions. For this condition, which was the most severe static load combination, the turbine was parked downwind at sea-level, with its blades flat to the wind. The drag coefficient was assumed to be 1.6. The lower curve in Figure 3 shows these extreme bending moments plotted verses spanwise position.

Following the latest IEC safety standard, for the design of this blade a PSF of 1.35 was used to cover the 
uncertainty on loads and a PSF of 1.15 was used on the material strength. Typically, these design factors are given by the designer and are not questioned or altered by the blade test laboratories. The PSF on loads covers unfavorable uncertainties in predicting the characteristic loads for ultimate strength over a full design life.

The PSF of 1.15 on materials covers a range of uncertainties including errors in the stress or buckling calculation, property differences between the blade material and the material used to generate the test data (e.g. size effects, fiber content), manufacturing or geometric differences between the design and the asbuilt structure (e.g. blade to blade variations to account for strength variations in a population of manufactured blades), and adjustments to the characteristic strength to establish the probability of survival within a population. All of these influences are important but are already covered in the design and do not need to be accounted for again in the test. Therefore a material PSF of 1.0 is used on the test load.

A total design PSF of 1.35 was used to scale the characteristic loads to the design loads, and is shown in the middle curve of Figure 3.

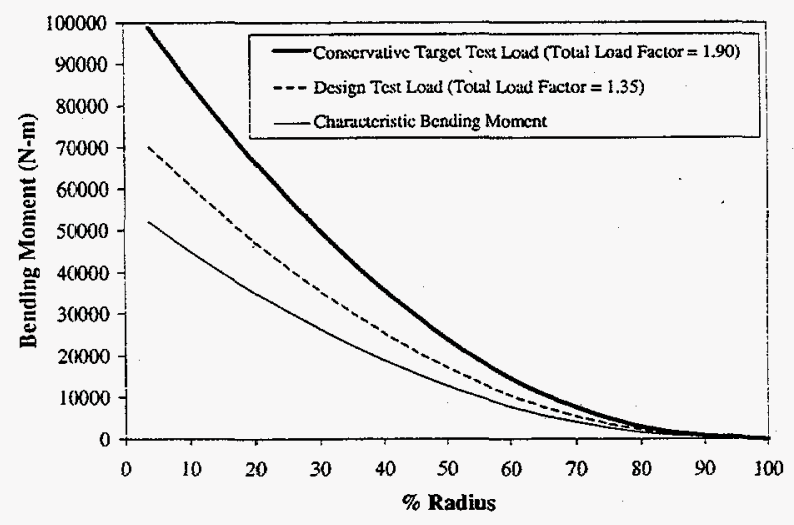

Figure 3 - Extreme Static Load Curves

TLFs were then used to scale the design loads to the load-based test loads. For the static strength test, two possible combinations of factors were considered and are given in Table 1. The least-conservative case used only the design loads as the test load with a PSF of 1.35 , while the conservative test load case had a total PSF on the characteristic loads of 1.9. A brief description of these additional test load factors is given below.

One factor that should be considered is to account for uncertainties introduced by the test itself. For a static test this category covers effects due to geometric alignment errors introduced by the test equipment or unfavorable differences between the applied test load and the target test load (eg. point loading). Under static testing, the blade must be able to survive its extreme static loads at the end of its design life. This factor could also account for the reduction in ultimate static strength experienced by a blade that has operated its full design life. For static testing the loading methods are generally straight forward and the uncertainties are deterministic. A relatively small TLF of 1.06 was applied to cover these unknowns.

Table 1 - Static Test Load Factors

\begin{tabular}{lcc}
\hline Partial Load Factors & $\begin{array}{c}\text { Design } \\
\text { Case }\end{array}$ & $\begin{array}{c}\text { Conservative } \\
\text { Case }\end{array}$ \\
\hline Uncertainty in Loads & 1.35 & 1.35 \\
Uncertainty in Materials & 1.00 & 1.00 \\
Test Uncertainties & 1.00 & 1.06 \\
Environmental Conditions & 1.00 & 1.33 \\
Total Load Factor & $\mathbf{1 . 3 5}$ & $\mathbf{1 . 9 0}$ \\
\hline
\end{tabular}

A more consequential TLF is used to account for the fact that the test environment is usually more benign than the operating environment. This factor is used during the design to account for the reduced strength under operating conditions and must be added back for the test when those strength reductions are not realized. This is illustrated in the strength probability distributions in Figure 1 which shows the test blades to be stronger than the in-service blades.

For the conservative case in Table 1 , a TLF of 1.33 is taken to account for environmental effects. For Douglas fir/epoxy used in the AOC $15 / 50$ blade, the material properties are very sensitive to environmental effects; particularly laminate moisture content (LMC) and temperature. Laminate moisture content is most important. Despite the protective interior and exterior paints and gel coats, LMC can vary significantly in a wind turbine blade depending on the environment that it is operated in. The material will absorb and retain moisture corresponding to the nominal ambient humidity. Since LMC variability is so difficult to predict, a design condition of $12 \%$ wood moisture content (WMC) is used for all blades, regardless of the climate where it will be operated. A $12 \% \mathrm{WMC}$ is considered an extreme moisture condition, comparable to only a few tropical locations. Typical LMCs of manufactured blades tested in the laboratory are estimated at about $7 \%$. This favorable $5 \%$ decrease in moisture content in the test blade corresponds to an additional $20 \%$ increase in blade strength based on the 


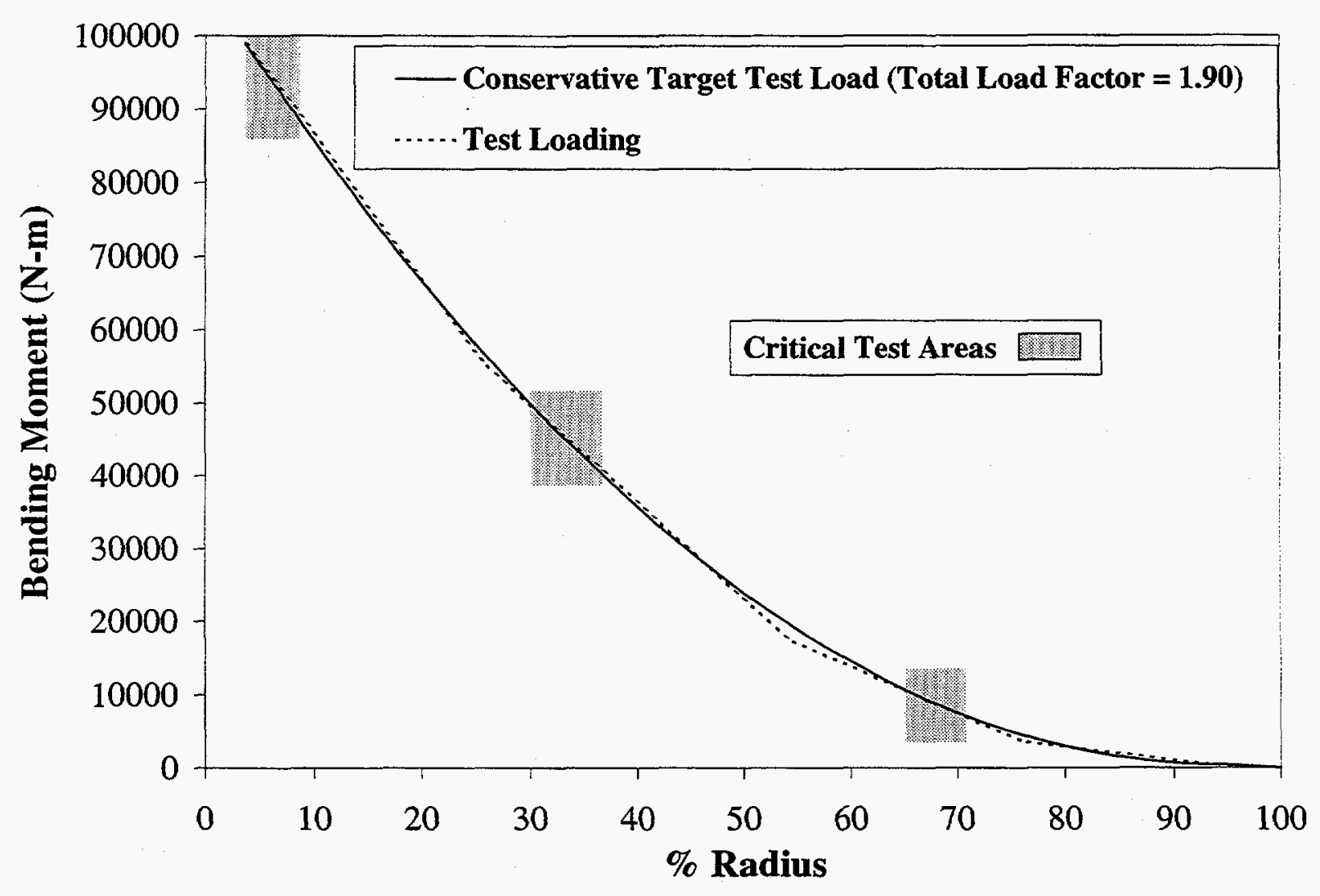

Figure 4 - AOC 15/50 Static Target Loads and Test Loads

predicted AOC 15/50 compression side static failure. (In tension the effect of LMC is approximately three times less)

Temperature also plays a major role. An $8.9^{\circ} \mathrm{C}\left(16^{\circ} \mathrm{F}\right)$ rise in temperature above average laboratory temperature corresponds to a $10 \%$ strength reduction at the design condition of $12 \%$ moisture content. Taken together, the effect of temperature and LMC correspond to a total environmental factor of 1.33 if the design hot/wet condition is assumed

The total factor of 1.9 for the AOC $15 / 50$ blade is probably realistic but the authors' caution that these same TLFs should not be arbitrarily applied to other blades without a comprehensive evaluation of the blade materials, design, and test methodology. We use the conservative case in our analyses to provide a fair comparison to the strength-based method.

Figure 4 shows a plot of the conservative target test loads along with the applied test loads. The applied test loads were found by fitting a segmented bending moment curve using concentrated point loads distributed along the span to approximate the target load curve. Each load point gave a straight line segment tangent to a portion of the target load curve. Four load points were determined to be the minimum number required to match our test load criteria of less than a 5\% deviation from the target loads, from the root to $95 \%$ span. Critical test areas were avoided in selecting the load points, as the load-introduction equipment can alter the strength of the structure.

Static Strength-Based Testing

A strength-based test load was developed using the predicted mean blade strength shown in Figure 5. The strength curve shows the predicted ultimate failure strength of the AOC 15/50 blade over its entire span for the center of the strength distribution shown in Figure 1.

The strength curve is determined by section analysis at $10 \%$ spanwise steps along the blade. The analysis technique accounts for the airfoil shape at each station and works inward in layers, accounting for exterior gel coat, exterior glass skin, structural shell lamination of Douglas fir/epoxy, and interior glass skin. The shear web and its bonding stringers are also included in the 
analysis. The section analysis results in a list of blade properties, including weight-per-unit-length, flatwise and edgewise stiffness and strength, and center-ofgravity location. The spanwise strength distribution, shown in Figure 5, is adjusted for the expected laboratory temperature $\left(21.1^{\circ} \mathrm{C}\right)$ and laminate moisture content of the test blades (7\%).

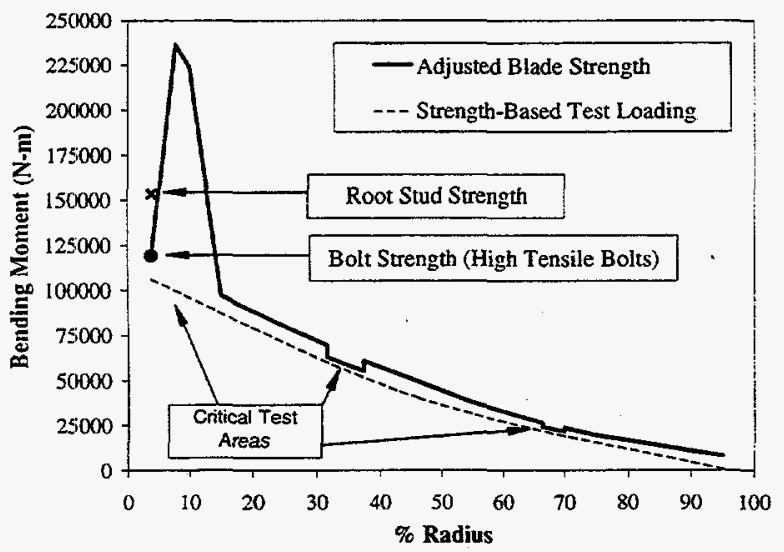

Figure 5 - AOC 15/50 Design Strengths and Static Strength-based Test Loads

There are two elements that determine the strength of the root joint: the stud pull-out strength and the bolt strength. Analysis showed the bolts to be the weakest root element. Using high grade bolts with a yield strength of $1103.2 \mathrm{MPa}(160,000 \mathrm{psi})$, the root withstood a nominal moment of $108,487 \mathrm{~N}-\mathrm{m}(80,000$ $\mathrm{ft}-\mathrm{lbs})$ before yield and $122,220 \mathrm{~N}-\mathrm{m}(90,000 \mathrm{ft}-\mathrm{lbs})$ before ultimate failure. The predicted pull-out strength of the root studs was $149,380 \mathrm{~N}$-m $(110,000 \mathrm{ft}-\mathrm{lbs})$ based on ramp-loading tensile tests on single studs.

The strength of the butt joints was shown to be approximately $10 \%$ lower than that of the surrounding laminates. Although the butt joint regions lower the blade strength, the effect of butt joints on the strength of Douglas fir veneers is well documented and can be included in the design with high confidence.

The strength-based test load distribution was found in the same manner as for the load-based test load. Given the target strength curve, the test load was fit to match the curve at the critical test areas. Because the strength of the critical areas is lower, a segmented static test load distribution could easily pass through all three critical locations on the target curve with only two load points. Because the root strength was determined by the strength of the bolts, which have a lower degree of uncertainty, it was decided to weight the loading to favor a failure of the shell by lowering the root bending moment to $90 \%$ of the load that would result in static failure. This knockdown ensures that the blade's outboard region $(35 \% \mathrm{R})$ will be more severely tested than root features such as studs and bolts. To the blade designer, this information has more intrinsic value than a bolt failure. However, if a lower-than-expected stud strength did exist, a stud failure would still occur and could be addressed.

Figure 5 shows the test loads and target test loads for the AOC $15 / 50$ blade. This is the test load distribution that will be applied in static strength tests planned at NREL. A whiffle tree is used to apply the test load to the blade by distributing a single-point load to multiple (two) points along the span of the blade.

The layout of the AOC $15 / 50$ blade and whiffle tree for the static strength-based test is shown in Figure 6.

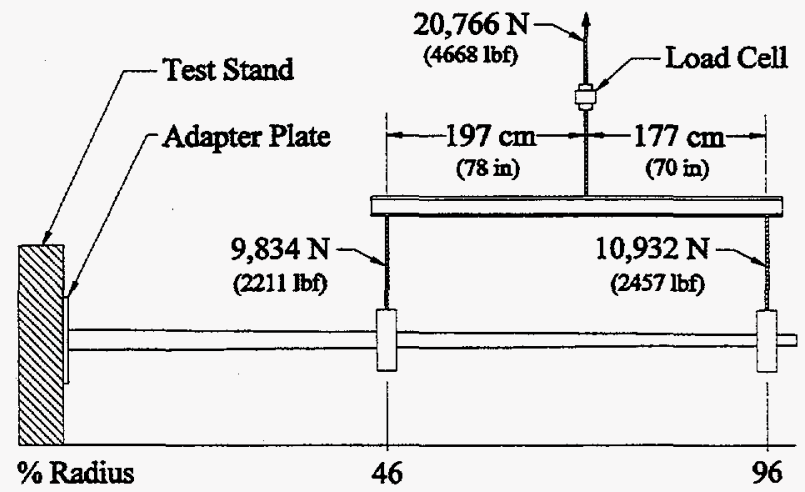

\section{Figure 6 - AOC 15/50 Whiffle Tree Configuration}

Figure 7 shows both the static load-based and strengthbased target test load curves for the AOC $15 / 50$ blade. It shows that the strength curve lies above the loadbased scenarios considered.

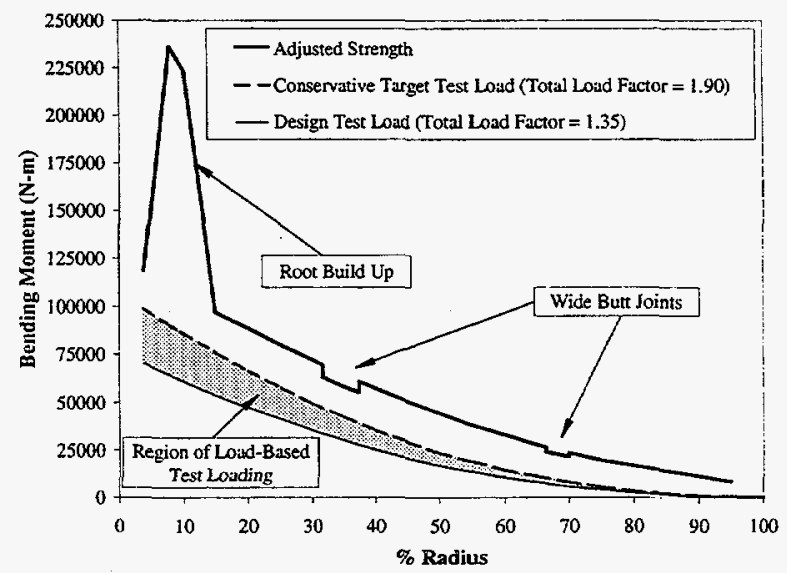

Figure 7 - Comparison of Static Load-based Test Loads and Strength-based Test Loads 
Figure 8 compares the strength- and load-based test loads. Note that even with the root strength knockdown of $10 \%$ on the strength-based test load, the strengthbased curve exceeds the load-based curve. If a blade manufacturer desired to verify a design under a more severe set of standards, the strength-based test results could probably be used without retesting, assuming the mean design strength was realized.

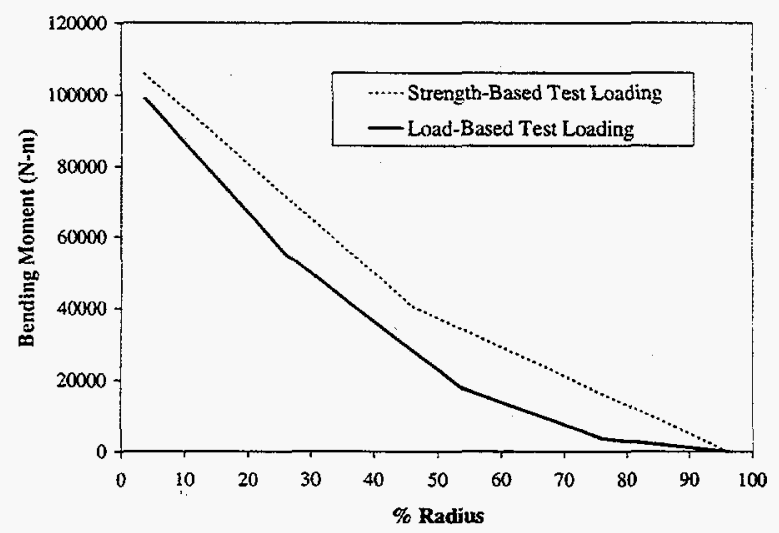

Figure 8 - Strength and Load-based Test Loads

\section{Fatique Testing}

\section{General Fatigue Approach}

The same general approach used in static testing was used to develop the strength and load-based analyses for fatigue testing; however, the procedure is significantly more complex. To establish the test load on the basis of either operating loads or design strength, some information about the material strength properties must be known. For a load-based test, the operating loads must be transformed into an equivalent test load spectrum that can be applied using the available equipment in a reasonable amount of time. This transformation requires $\mathrm{S}-\mathrm{N}$ data and detailed blade design information. Since the operating loads occur throughout many mean levels and amplitude ranges, the load evaluation must include corrections that use a Goodman Diagram for differences in stress amplitude ratios, $R$. (The ratio of the minimum stress over the maximum stress). + For strength based-testing, the S-N curves determine the loading.

\section{Load-based Fatigue Testing}

AOC 15/50 Fatigue Test Loads- First, fatigue operating loads for several blade locations were obtained from field test data. Operating loads data were

+ The term "load amplitude ratio" is used in this paper to define the ratio between the minimum and maximum loads applied to the specimen. It should not be confused with the $\mathrm{R}$ value or stress ampiitude ratio, which refers to the stress in the blade, as more than one $R$ value can exist for a single load amplitude ratio. available for the root, $45 \%$ radius, and $75 \%$ radius. Test data for $35 \%$ radius were not available.

The limited test data was binned and scaled to the 30 year design life. Extreme loading and rare events were extrapolated linearly from the log-normal plot, extending the load spectrum to include the low-cycle high-load bins that are not seen in the relatively short sample of test data. ${ }^{10}$

The two critical areas to be tested in fatigue were the root and $35 \%$ radius, the location of the veneer butt joints. These two stations had the lowest reserve margin.

Next, data for the three known spanwise load spectra were interpolated to determine the load spectrum at $35 \%$ radius. This interpolation was done using a regression analysis for the three known stations. The resulting $35 \%$ radius loading distribution along with the data for the root, $45 \%$, and $75 \%$ radial stations are shown in Figures 9 and 10.

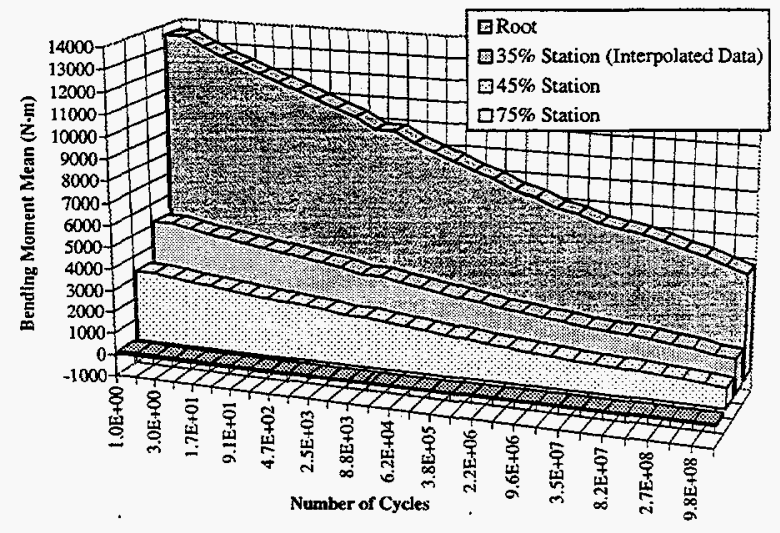

Figure 9 - 30-Year Operating Loads for AOC 15/50 Blade - Mean Bending Moment

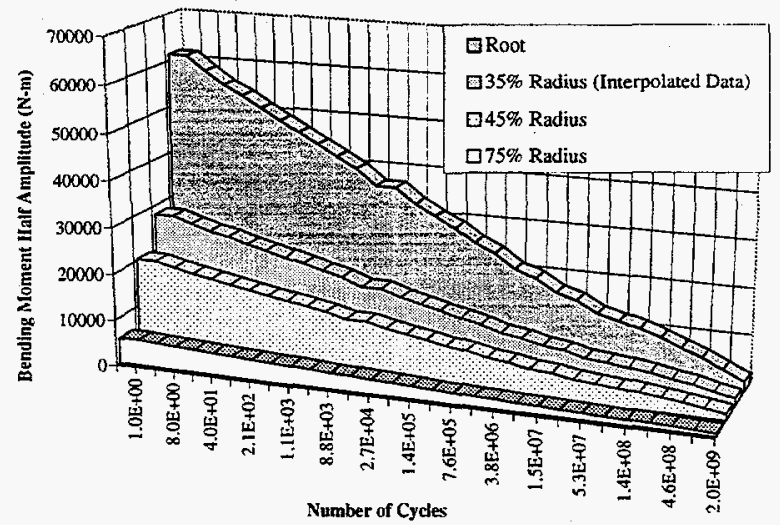

Figure 10 - 30-Year Operating Loads for AOC 15/50 Blade - Half Amplitude Bending Moment 
Fatigue Load Factors - The representative load distributions from Figures 9 and 10 for the root and $35 \%$ radius were scaled to account for the design uncertainties and test conditions. To illustrate the method of using test load factors to establish the fatigue test loads on the basis of design loads, three test scenarios were chosen which represent a realistic range of load factor values for the AOC $15 / 50$ blade. These are given in Table 2. The first scenario, which was considered non-conservative, uses just the design loads as the test load. No other influences are considered. Next, a moderate case was considered where the resulting total test load factor was 1.55 . A conservative case was represented by a total test load factor of 1.75 .

Although the version IEC safety standards used does not require a factor on the fatigue design loads, a factor of 1.25 is required to cover the consequences of failure. This is because in non-fail-safe components, such as blades, a failure would lead rapidly to failure of the major wind turbine system. For a fatigue test this PSF is applied to the test loads. It is shown in Table 2 as a factor on loads uncertainty.

As previously discussed, any PSF used in the design to cover material uncertainties should not be applied to the test load since the test blade material is the actual material in the design.

Table 2. Fatigue Load Factor Combinations

\begin{tabular}{lccc}
\hline Partial Load Factors & $\begin{array}{c}\text { Design } \\
\text { Case }\end{array}$ & $\begin{array}{c}\text { Moderate } \\
\text { Case }\end{array}$ & $\begin{array}{c}\text { Conservative } \\
\text { Case }\end{array}$ \\
\hline Uncertainty in Loads & 1.25 & 1.25 & 1.25 \\
Uncertainty in Materials & 1.00 & 1.00 & 1.00 \\
Test Uncertainty & 1.00 & 1.06 & 1.12 \\
Environmental Conditions & 1.00 & 1.17 & 1.25 \\
Total ILoad Factor & $\mathbf{1 . 2 5}$ & $\mathbf{1 . 5 5}$ & $\mathbf{1 . 7 5}$ \\
\hline
\end{tabular}

Next a partial test load factor is given to cover uncertainties introduced by the test. For a fatigue test, this factor includes uncertainties in the fatigue formulation, load amplification, and geometric alignment errors introduced by the test equipment or unfavorable differences between the applied test load and the target test load. For example, to develop the test loads it was necessary to transform the design loads by calculating a fatigue loading plan that exercises the blade with an equivalent damage accumulation in an accelerated time span at constant amplitude. The equivalent test loading deviates greatly from the

¥ It should be noted that there is no general agreement on an appropizate total test load factor that can be applied to all blades or which factors should be applied. The factors given are for the AOC $15 / 50$ blade design tested at NREL's facilities. original design loads shown in Figures 9 and 10. Thus some uncertainty, stemming from limits of S-N data and shifts in the $R$ ratio, is introduced by this transformation. For the AOC $15 / 50$ blade a factor of 1.06 was used for the moderate case and 1.12 was used for the conservative case. These factors are larger than for the static test because there is inherently more uncertainty in the fatigue loads evaluation.

As with the static test, the fatigue test loads must be scaled by a factor that accounts for the difference in environmental conditions. As discussed previously the differences are substantial when the hot/wet design condition is represented in the test laboratory. For the AOC $15 / 50$ blade a factor of 1.17 was used for the moderate case and 1.25 for the conservative case. The fatigue TLFs are lower than the static TLF for environmental effects because in the fatigue case this factor is more representative of the average conditions rather than a worst case condition. Nevertheless, since wood material properties degrade rapidly with increasing temperature and laminate moisture content, a large environmental test load factor must be assumed for fatigue as well. For the high cycle fatigue test planned at NREL, a tension side failure is predicted; but when the blade strength is adjusted back to the $12 \%$ WMC design condition, a compression side failure is more likely. This shift from tension data to compression data increases the sensitivity to the environment by over a factor of three, which must be accounted for in the TLF.

Calculating Equivalent Damage - Once the above load spectra were scaled to the appropriate levels they were converted to equivalent test loads, which involved a simplification to constant amplitude loading and an amplification to accelerate the test. This transformation requires applicable S-N curves for each of the blade stations taken at the proper $\mathrm{R}$ ratio and accurate section data to convert loads into stresses at each section. The incremental damage from each bin of the scaled operating loads was computed using a conventional Palmgren-Miner linear damage approach. The total damage due to the scaled operating loads was computed. An additional correction to convert the S-N curves for operating $R$ ratios, to the $R$ ratio of the constant amplitude test loads was also necessary. From the adjusted S-N curves for the material, a constant amplitude load could be selected to give the same damage as the load spectrum.

Figure 11 shows the load amplitude ratios for the operating loads of the root and $35 \%$ station. Also shown are the load amplitude ratio of the final test load 
which was determined through strength-based analysis. The test load could have been chosen to match the operating loads more closely (e.g. $\mathrm{R}=-0.6$ ) however, most of the reliable material test data currently available were taken at $\mathrm{R}=0.1$.

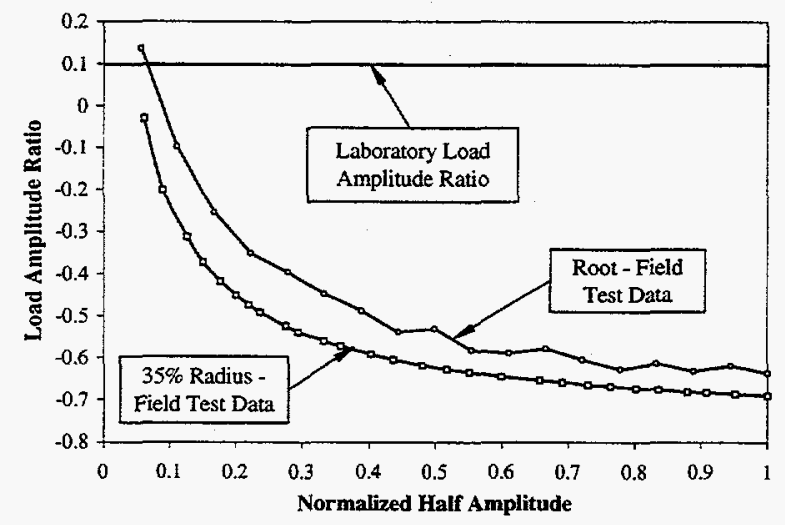

Figure 11 - Load Amplitude Ratios for the Operating Load Spectra and Constant Amplitude Test

In Figure 12, the damage rate at the most severely stressed portion of the two critical AOC 15/50 blade cross sections was calculated for a wide range of test load factors to illustrate the sensitivity of the above analysis. A relatively small variation in any of the partial load factors can lead to a significant change in the damage rate; therefore, the test load factors must be carefully considered in order to ensure valid results. If the damage for a specific loading is equal to or greater than one, the blade is theoretically expected to fail. The damage value varies exponentially with the load factor applied to the operating loads. The points at which the curves cross the damage-equals-unity line are the point of theoretical failure.

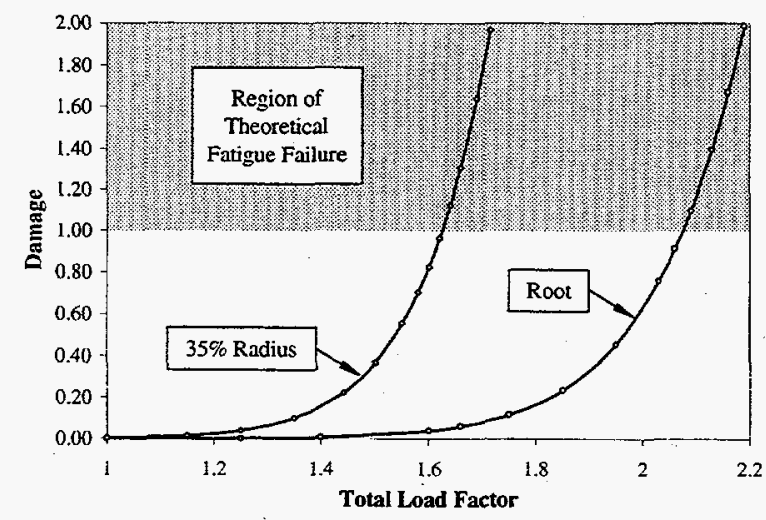

Figure 12 - Damage Variation for Load-Based Fatigue Tests with Total Test Load Factor
The graph shows that the $35 \%$ station will fail first; however, the key point of this graph is to show that the variation in damage between the design loads (total factor $=1.25$ ), the moderate test loads (total factor = 1.55) and a conservative test loads (total factor $=1.75$ ) is nearly two orders of magnitude. Even a comparison between the 1.55 factor and the 1.75 factor yields a damage difference of five to one.

\section{Strength-based Fatigue Testing}

The transformation from blade strength data to a similar test load spectrum is more straight-forward. The S-N curves for the blade materials determine the test load directly. Adjustments must be made to account for material differences and uncertainties outside of the design situation. The fatigue test loads are derived from the as-manufactured blade $\mathrm{S}-\mathrm{N}$ data representative of the average blade material properties in the region(s) of greatest importance. The $\mathrm{S}-\mathrm{N}$ curves are adjusted to account for the room temperature blade test condition and the as-manufactured blade moisture content, since the fatigue performance of the laminated fir/epoxy blade shell is directly influenced by both. These influences have been characterized experimentally and standard procedures for applying the correction factors were used. ${ }^{11}$ A small correction for the volume of material in the blade versus that in the sub-structural laboratory material tests is also made, although this has a rather small impact. A separate set of fatigue curves, based on other tests, is used for the root studs since their fatigue response (not surprisingly) is quite different than that of the blade shell.

The test loading is determined at each of the critical test areas. Each tested area experiences fatigue loading conditions that will cause a total accumulation of damage equal to one for a fixed number of cycles. The method for performing these analyses is described below for the AOC $15 / 50$ blade design. Tests based on these results are currently in progress.

\section{AOC 15/50 Strength Analysis}

Using the blade strength data, a tension side limit in the test laboratory was computed for the shell at $35 \%$ radius, the location of the first series of wide butt joints. As discussed earlier, the predicted failure location will shift to the compressive side of the blade for the design condition, which is more adversely affected by environmental influences. The laminate strength of the blade at $35 \%$ radius was found using $\mathrm{S}-\mathrm{N}$ curves for Douglas fir/epoxy wide butt jointed laminate in both tension and compression. For $35 \%$ radius, an $S-N$ curve was chosen for $R=0.1$ and $R=10$ tests conducted parallel to the grain in laminated, butt-jointed Douglas 
fir/epoxy specimens. The specimens had a test section volume of $205.2-\mathrm{cm}\left(31.8 \mathrm{in}^{2}\right)$, veneer grade $\mathrm{A}$, and a test temperature of $21.1^{\circ} \mathrm{C}\left(70^{\circ} \mathrm{F}\right)$. The strength data was corrected for a $7 \%$ laminate moisture content. ${ }^{11}$ For a load amplitude ratio of 0.1 , the tension side of the blade was represented by the $R=0.1$ test data while the $R=10$ data represents the compression side butt joints. The other critical area was at the root. Experimental data from root stud fatigue tests conducted by Gougeon Brothers Inc. were used to derive an $\mathrm{S}-\mathrm{N}$ curve for $\mathrm{R}=0.1$ stud cycle life.

The objective was to design a test load that would reach theoretical blade fatigue failure for an average blade at $35 \%$ radius at a cycle count near three million while loading the root to only $90 \%$ of its expected load capacity. A $5.18-\mathrm{m}(17 \mathrm{ft})$ long test article with an actuator load of $12,432 \mathrm{~N}(2800 \mathrm{lb})$ was necessary to reach $100 \%$ damage at 2.92 million cycles. This achieved the desired objective for the test.

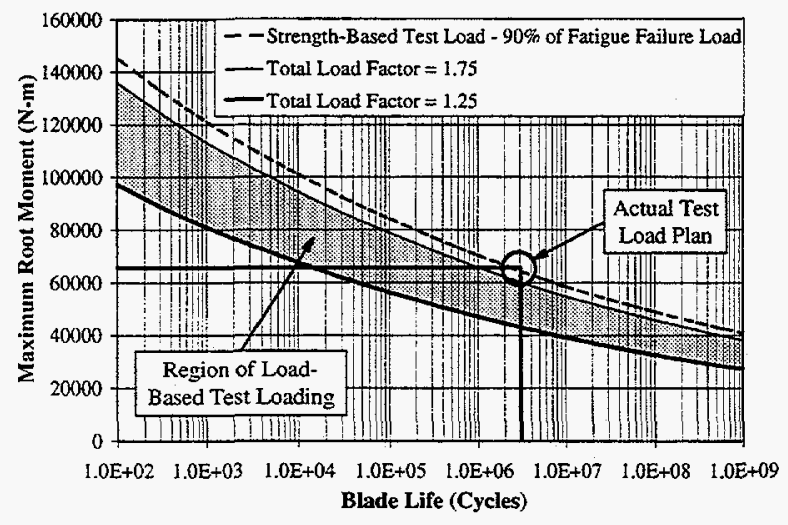

Figure 13 - Comparison of Strength-and Load-based Fatigue Test Loading for the AOC 15/50 Root Station

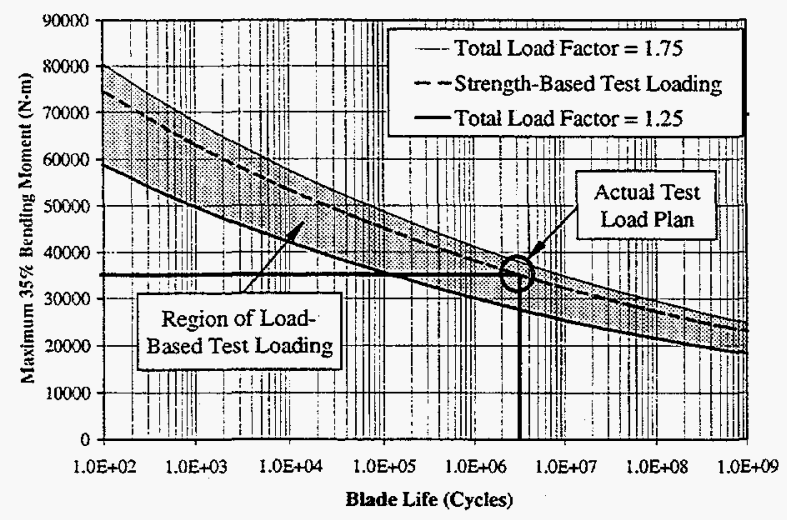

Figure 14 - Comparison of Strength-and Loadbased Fatigue Test Loading for the AOC $15 / 5035 \%$ Station - Tension-side Butt-jointed Veneers
Figures 13 and 14 compare the strength-based and loadbased analysis methods described above. Figure 13 is for the root analysis and Figure 14 shows analysis for the $35 \%$ radius. Each curve represents equivalent test loading in fatigue for a range of constant amplitude fatigue tests at a constant total load factor. The shaded band represents the region of test loading which would result from various test load factor combinations. The lower boundary of this region reflect the design loads as described in Table 2. The upper boundary reflects the conservative test factors ( $\mathrm{PSF}=1.75$ ). The constant amplitude test of $12,432 \mathrm{~N}$ (2800 lbs) applied at $5.18 \mathrm{~m}$ (17 $\mathrm{ft}$ ), described above is shown as a single point on the curve. The strength-based test load is shown within the shaded region for $35 \%$ radius, bracketing the loadbased test cases and is based on the mean failure strengths. This indicates that for more conservative test load cases (test factors $>1.60$ ), some AOC $15 / 50$ blades would not have sufficient strength. These situations are representative of more extreme environments where high moisture and temperature will dictate a compression side failure.

\section{Summary and Conclusions}

Two methods for developing blade test loading have been demonstrated using the AOC 15/50 blade as the test specimen: load and strength-based testing. Tests were designed for both cases under fatigue and static loading. Plans are underway to test blades using the strength-based methods described.

Load-based tests demonstrate a blade's ability to carry a particular load or combination of loads. Load-based tests use design partial safety factors in conjunction with test load factors to arrive at conservative test loads accounting for test specific uncertainties, while strength-based tests use the computed strength.

Results show that fatigue damage rates are extremely sensitive to test load factors and should be carefully considered when assigning values to them. Test load factors used by the load-based cases are controversial and vary moderately among the world's test laboratories. This variability could cause tests accepted by some standards to be invalid under others.

Strength-based tests verify the as-built manufactured strength of the blade by matching the test load to the spanwise strength distribution. Under static loading, the strength-based test gave a more conservative result than any of the load-based tests considered. In fatigue, the same was true, except when adjusting for a severe hot/wet operating environment. The strength-based tests were thus generally more conservative because the 
reserve strength was included in the test load. Under a strength-based test, a re-evaluation of the load case can be made without conducting a new test.

The strength-based tests to failure described in this paper will give the best information on actual blade strength but will prevent further testing of the blade. If a single blade is required to survive multiple load combinations, proof load testing to the predicted $95 \%$ survival value for test blade strengths is recommended.

\section{Acknowledgments}

The authors would like to recognize the organizations and people responsible for making this project happen. The structural testing team at NREL, and Atlantic Orient Corporation, are recognized for their dedication and support for this project. Special thanks to Scott Hughes who edited and compiled many of the figures and text through multiple stages of the review process. Individual contributions were also made by Jim Johnson, Mike Jenks, Darren DeShay, Bill Gage, Bob Keller, and Trudy Forsyth at NREL, who are acknowledged with appreciation. Bob Sherwin is congratulated for permitting the dissemination of data contained in this paper, and Bruce Johnson for his support of the work. Finally, the U.S. Department of Energy is thanked for its continued support and funding of structural testing at NREL.

\section{References}

1. van Grol H.J., "Strength and Fatigue Testing of Large Size Wind Turbine Rotors: Volume 1: Rationale and Directions" , ECN-C--95-052, Annex B, June 1996.

2. van Delft, D.R.V "IEC-TC88-WG8 Testing of Rotor Blades", IEA Joint Action Proceedings Wind Turbine Fatigue, $4^{\text {th }}$ Symposium Suttgart, February 1-2, 1996, pp 91-96.

3. van Delft, D.R.V., and van Leeuwen, J.L. "Full Scale Fatigue Testing of Wind Turbine Rotors", Presented at the IEA experts meeting "Wind Turbine Fatigue", April 1994, Petten, Netherlands.

4. van Grol H.J., Bulder B.H., "Reference Procedure to Establish Fatigue Stresses for Large Size Wind Turbines, a State of the Art Report, Volume 1: Main Body of the Report and Annexes", ECN-C--94-013, pp. 146-147, February 1994.
5. Collins, J.A. Failure of Materials in Mechanical Design John Wiley \& Sons, pp. 241-244, 1981.

6. ISO-2394 Standard "General Principles on Reliability for Structures" Second Edition 1986-10-15.

7. Zuteck, M.D., Musial, W.D., and Johnson, B., "Design and Fatigue Testing of the AOC $15 / 50$ Wind Turbine Blade", Windpower '93 Proceedings, San Francisco, CA, pp. 374-380. 1993.

8. Spera, A.S., Esgar, J.B., Gougeon, M., and Zuteck, M.D. Structural Properties of Laminated Douglas Fir/Epoxy Composite Material, NASA Reference Publication, DOE/NASA/20320-76, pp. 105, May 1990.

9. Bakker, D. International Electro-technical Commission TC88 IEC1400-1: Second Edition 1996-2 "Wind Turbine Generator Systems, Part 1: Safety Requirements", March 1996.

10. Kelley, N.D., "The Identification Of Inflow Fluid Dynamics Parameters That Can Be Used To Scale Fatigue Loading Spectra of Wind Turbine Structural Components", NREL/TP-442-6008, November 1993.

11. Stroebel, T., Dechow C., and Zuteck, M.D. "Design of an Advanced Wood Composite Rotor and Development of Wood Composite Blade Technology", DOE/NASAV0260-1, NASA CR-171713, GBI ER-11, December 1984. 